\title{
Output Power Control Using Artificial Neural Network for Switched Reluctance Generator
}

\author{
Supat Kittiratsatcha, ${ }^{*}$ Paiwan Kerdtuad, ${ }^{2}$ and Chanin Bunlaksananusorn ${ }^{1}$ \\ ${ }^{1}$ Faculty of Engineering, King Mongkut's Institute of Technology Ladkrabang, Bangkok 10520, Thailand \\ ${ }^{2}$ Faculty of Engineering, Rajamangala University of Technology Isan Khonkaen Campus, \\ Khonkaen 40000, Thailand
}

(Received January 31, 2021; accepted June 14, 2021)

Keywords: switched reluctance generator, output power control, output power estimation, conduction angle estimation, artificial neural network

We propose an output power control of a variable-speed switched reluctance generator (SRG) by implementing an artificial neural network (ANN) in the control loop. In the high-speed operation with single pulse mode, the phase current waveform, and subsequently, the output power, depend on the conduction angles. The conduction angles, i.e., the turn-on and turn-off angles, can be determined by the proposed method using an ANN. A dynamic model of an SRG with eight stator poles and six rotor poles is used for simulation to obtain the output power profiles, which subsequently become the ANN training data. The inputs of the ANN are the reference value of the output power and the rotor speeds, while the outputs of the ANN are the turn-off and turn-on angles. The control algorithm is implemented by integrating the trained data into the dynamic model using MATLAB. The experimental setup of the SRG is implemented using a digital signal processor (DSP) to control the two-switches-per-phase drive system, which includes highly accurate phase current and dc-link voltage sensor circuits. The trained biases and weights of the ANN are also coded in the DSP. To validate the proposed method, comparisons are made between simulation and experimental results.

\section{Introduction}

In power generation, a switched reluctance generator (SRG) serves as a good alternative to a DC generator. SRGs are useful in a variety of applications, including the automotive industry, ${ }^{(1-4)}$ wind turbines, ${ }^{(5)}$ and aerospace power systems. ${ }^{(6)}$ The main characteristics of a typical SRG are the simplicity of the structure and low-cost power generation with high efficiency and torque over a wide range of speeds. Nonetheless, the doubly salient pole structure and core saturation effect of SRGs contribute to highly nonlinear magnetic characteristics and more torque ripples. The output power profiles of SRGs are also subjected to various factors, including the dc-link voltage, dc-load current, phase voltage, phase inductance, rotor position, and speed. Thus, the design of an optimal output power control for an SRG that accounts for all the influencing factors presents developers with challenges.

*Corresponding author: e-mail: supat.ki@kmitl.ac.th https://doi.org/10.18494/SAM.2021.3312 
Various SRG output power control methods have been proposed. The energy conversion process and the structures of the speed and power controllers of an SRG were proposed in Ref. 7. In Ref. 8, the optimized performance in the current-controlled mode was investigated. In Ref. 9, the output power profiles of an SRG in various applications were determined on the basis of the control variables and design, while in Ref. 10, a novel control system for variable-speed wind energy applications was discussed. A modeling method for the maximum power control of an SRG in wind turbines was presented in Ref. 11. In Refs. 12 and 13, a control strategy was proposed to enhance the output power by introducing a freewheeling mode to boost the phase current when switches were turned off. In Ref. 14, the optimal efficiency control of an SRG was determined from the optimal turn-on and turn-off angles in the single pulse mode, ignoring the nonlinear magnetization curves. In Ref. 15, a closed-loop control for high-speed SRGs was presented, whereby the optimal turn-off and turn-on angles were respectively obtained from an analytical curve fit and closed-loop power control. In Ref. 16, a control strategy by which the turn-on and turn-off angles were varied to achieve the optimal power and maximum efficiency through reductions in the dc-link ripple current was proposed. In Ref, 17, a closed-loop power control to achieve higher efficiency in SRGs, in which the optimal turn-on and turn-off angles were selected on the basis of given reference powers and rotor speeds, was investigated. Furthermore, there have been an increasing number of studies on applying an artificial neural network (ANN) in SR machine controls, such as in sensorless control, ${ }^{(18-20)}$ optimized torque control, ${ }^{(21)}$ speed control, ${ }^{(22)}$ and wind turbine control. ${ }^{(23)}$ However, there have been no studies on an output power control that incorporates an ANN. We thus propose an output power control for an 8/6 SRG using an ANN to estimate the conduction angles according to the speed and output demand. In the proposed method, the output power profiles of the SRG at several operation speeds served as the ANN training data sets.

The organization of this paper is as follows. Section 1 is the introduction. Section 2 explains the details of the output power equations. Section 3 shows the details of the ANN-based output power control scheme. Next, Sect. 4 deals with comparisons between simulation and experimental results to verify the proposed method. Finally, Sect. 5 concludes the paper.

\section{Output Power Equation of SRG}

The SRG waveforms when running in single-pulse-mode operation are illustrated in Fig. 1. The electric power $P_{p h}$ in a given phase is the sum of the powers in the generation and excitation stages. The generation and excitation powers of an SRG in the single pulse mode are derived as

$$
\begin{gathered}
P_{p h}=\frac{1}{T} \int_{0}^{T} v_{d c} i_{p h} d t, \\
P_{e x c}=\frac{m}{\theta_{r r}} \int_{\theta_{o n}}^{\theta_{o f f}} v_{d c} i_{e x c} d \theta_{a},
\end{gathered}
$$



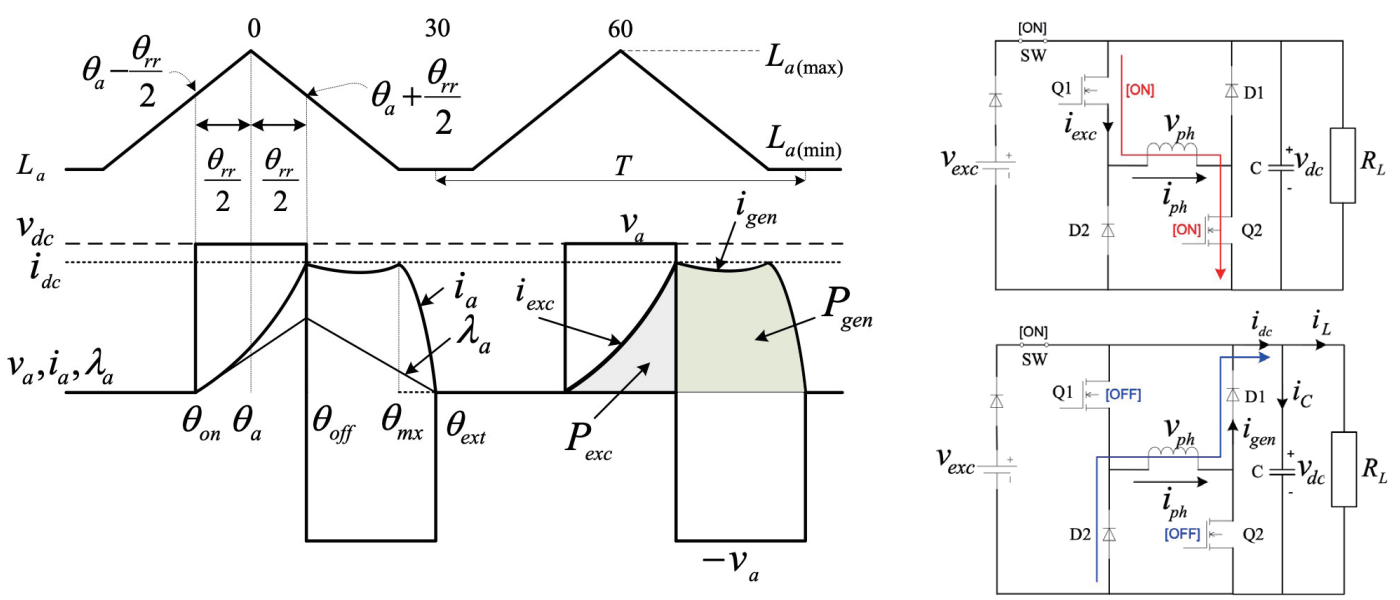

Fig. 1. (Color online) Operation waveforms of an SRG in single pulse mode.

$$
P_{\text {gen }}=\frac{m}{\theta_{r r}} \int_{\theta_{\text {off }}}^{\theta_{\text {ext }}} v_{d c} i_{\text {gen }} d \theta_{a},
$$

where $P_{p h}$ is the power of a given phase, $P_{e x c}$ is the excitation power, $P_{g e n}$ is the generated power, $i_{p h}$ are phase currents (i.e., $\left.i_{a}, i_{b}, i_{c}, i_{d}\right), m$ is the number of phases, $\theta_{r r}$ is the rotor pole arc, and $T$ is the duration of one phase operation.

The input power $P_{i n}$ of the SRG drive is the product of the average torque $T_{m}$ and the rotor speed $\omega_{r}{ }^{(24)}$ The average output power $P_{\text {out }}$ can be calculated by multiplying the dc-link voltage $v_{d c}$ by the dc-load current $i_{L}$. The input power and output power are expressed as follows:

$$
\begin{gathered}
P_{\text {in }}=T_{m} \omega_{r}, \\
P_{\text {out }}=v_{d c} i_{L} .
\end{gathered}
$$

\section{Output Power Control Using ANN}

In single-pulse-mode operation, the output power of an SRG depends on the phase current waveform, which in turn depends on the turn-off angle $\theta_{\text {off }}$ and turn-on angle $\theta_{\text {on }}$ and the rotor speed $\omega_{r}$ It is thus possible to control the variable-speed output power by varying the turn-off and turn-on angles. In this output power control scheme design into which an ANN was incorporated, the SRG output power profiles at various operation speeds are very important. Therefore, in this section, we propose how to create output power profiles.

\subsection{8/6 SRG output power profiles}

The $8 / 6$ output power profiles can be derived from the simulation of a dynamic model or the experimental results of an SRG drive. For this research, a dynamic model of the 8/6 SRG (Fig. 2) 
based on the magnetizing data from finite element analysis (FEA) was simulated to determine the output power profiles at various speeds and conduction angles. ${ }^{(25)}$ In Fig. 2, the conduction angle commands $\left(\theta_{\text {on }}{ }^{*}, \theta_{\text {off }}{ }^{*}\right)$ were adjusted to generate the optimal electric output power. The output power was calculated by multiplying the rms value of the dc-link voltage $v_{d c}$ by that of the dc-load current $i_{L}$. In the experiments, the speed was varied between 5000 and $7000 \mathrm{rpm}$, and iterative searches for the output power profiles were performed at speeds of 5000,6000, and $7000 \mathrm{rpm}$. Figure 3 illustrates the simulated output power profiles at the three speeds.

In Fig. 3(a), in which the SRG operated at a speed of $5000 \mathrm{rpm}$, the turn-on and turn-off angles were 49 and $12^{\circ}$, respectively, to obtain an output power of $1800 \mathrm{~W}\left(P_{\text {out }}=1800 \mathrm{~W}\right)$. In

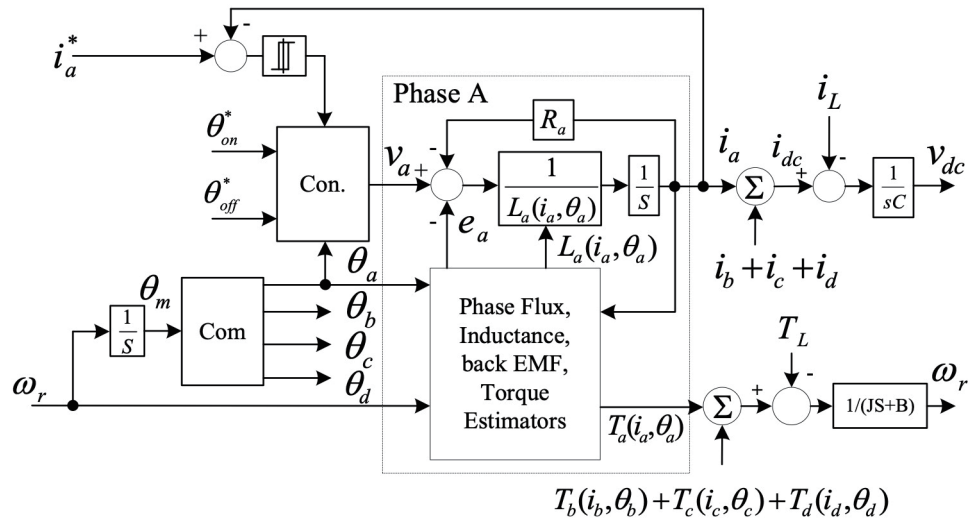

Fig. 2. Dynamic model of $8 / 6$ SRG based on FEA data.

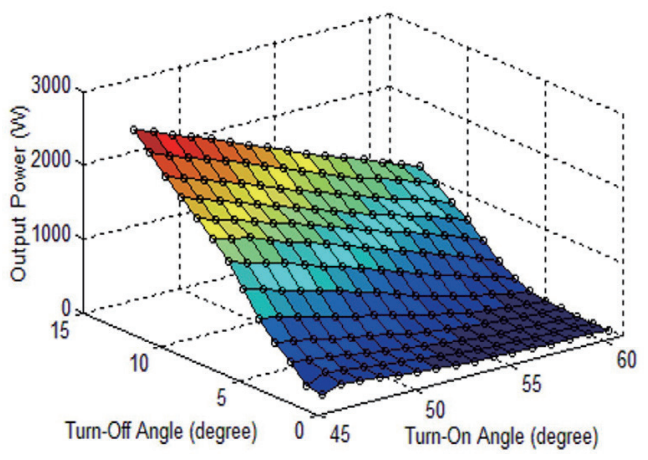

(a)

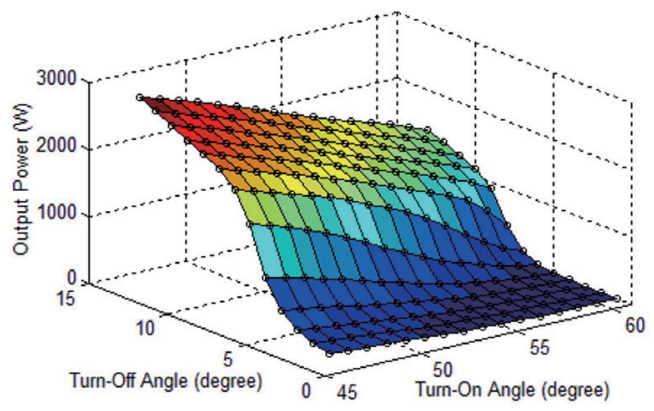

(b)

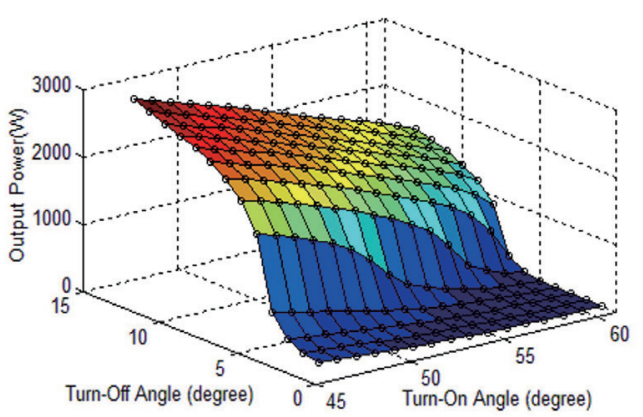

(c)

Fig. 3. (Color online) Output power profiles at speeds of (a) 5000, (b) 6000, and (c) $7000 \mathrm{rpm}$. 
Fig. 3(b), when the SRG operated at a speed of $6000 \mathrm{rpm}$, the turn-on and turn-off angles were adjusted to 52 and $10^{\circ}$, respectively, to obtain an output power of $1800 \mathrm{~W}\left(P_{\text {out }}=1800 \mathrm{~W}\right)$. In Fig. $3(\mathrm{c})$, where the speed was $7000 \mathrm{rpm}$, the turn-on and turn-off angles were respectively 50 and $9^{\circ}$ to maintain $P_{\text {out }}=1800 \mathrm{~W}$. To automate the tuning of the conduction angles in response to a variable speed, we incorporated an ANN into the dynamic model for automatic tuning of the conduction angles to maintain the output power at the load.

\subsection{Multilayer neural network}

The proposed ANN structure, shown in Fig. 4, was utilized to define the optimal turn-off angle $\theta_{o f f}{ }^{A N N}$ and turn-on angle $\theta_{\text {on }}{ }^{A N N}$ corresponding to the output power $P_{\text {out }}$ and the variable speed $\omega_{r}$ of an SRG. ${ }^{(26)}$ Such a network comprised three layers, i.e., the input layer $(R)$, the hidden layer $(S)$, and the output layer $(T)$.

The inputs of the ANN consist of the output power $P_{\text {out }}$ and speed $\omega_{r}$. The output power was calculated by multiplying the dc-link voltage $v_{d c}$ by the load current $i_{L}$. The rotor speed $\omega_{r}$ was calculated by counting the pulse of the incremental encoder. The input layer's activation function was a tangent sigmoid transfer function. In the hidden layer, the relationship between the inputs and outputs of the input layer can be expressed as

$$
\begin{gathered}
n_{1}=\sum_{i=1}^{2} I W_{1, i} \cdot p_{i}+b_{i}, \\
a_{1}=\tan \operatorname{sig}\left(n_{1}\right) .
\end{gathered}
$$

The network outputs comprise the turn-off angle $\theta_{o f f}{ }^{A N N}$ and turn-on angle $\theta_{o n}{ }^{A N N}$. A linear transfer function is chosen as the activation function in the output layers. The relationship between inputs and outputs in the output layers is shown by the following equations:

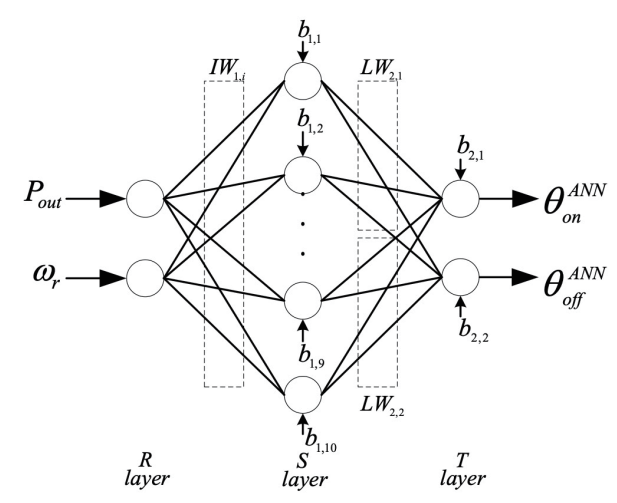

Fig. 4. Proposed ANN structure for estimating the turn-on and turn-off angles (conduction angles) of the SRG. 


$$
\begin{gathered}
n_{2}=L W_{2,1} \cdot a_{1}+b_{2}, \\
\theta_{o n}^{A N N}=a_{2}=\operatorname{purlin}\left(n_{2}\right), \\
n_{3}=L W_{3,1} \cdot a_{1}+b_{3}, \\
\theta_{o f f}^{A N N}=a_{3}=\operatorname{purlin}\left(n_{3}\right) .
\end{gathered}
$$

\subsection{Training data sets of the ANN}

In this research, the output powers at various turn-on and turn-off angles were collected from the simulated dynamic model, as depicted in Fig. 2. They were used as the training data sets. The simulations in single pulse mode were carried out at the selected speeds of 5000,6000, and $7000 \mathrm{rpm}$. The training data sets contained the relationships between the output power and the conduction angles at these speeds. The conduction angles were adjusted within the optimal area to optimally generate the electric output power. The parameters of the 8/6 SRG are given in Table 1; the turn-on angle $\theta_{\text {on }}{ }^{*}$ can be adjusted from 45 to $60^{\circ}$ before the aligned position. Also, the turn-off angle $\theta_{\text {off }}{ }^{*}$ can also be adjusted between 1 and $15^{\circ}$ after the aligned position. As shown in Fig. 5(a), the training data set at each selected speed consisted of 225 operation points, giving rise to 675 points for the three selected speeds. Figure 5(b) illustrates the targeted turn-off angle $\theta_{\text {off }}{ }^{\text {(Target) }}$ and turn-on angle $\theta_{\text {on }}{ }^{\text {(Target) }}$ of the neural network.

\subsection{Feed-forward algorithm}

The output power profiles were input to train a multilayer feed-forward algorithm using the MATLAB $^{\mathrm{TM}}$ Neural Network Toolbox. ${ }^{(27)}$ For each number of neurons, the network was trained multiple times, and the optimal number of neurons in the hidden layer $(S)$ was 10 neurons. The matrix size of the input weight $I W_{1, i}$ was thus $[10 \times 2]$, while the bias $b_{1}$ matrix size was $[10 \times 1]$. The output layer $(T)$ consisted of two layers: the first layer estimated the turn-on angle $\theta_{\text {on }}{ }^{A N N}$ and the second layer estimated the turn-off angle $\theta_{o f f}^{A N N}$. The weight matrices of the output

Table 1

Specifications of the $8 / 6$ SRG.

\begin{tabular}{lcc}
\hline Items & Value & Unit \\
\hline Rated power & 2.32 & $\mathrm{~kW}$ \\
Rated speed & 6000 & $\mathrm{rpm}$ \\
Rated voltage & 48 & $\mathrm{~V}$ \\
Stator pole arc & 26.8 & degree \\
Rotor pole arc & 27.8 & degree \\
Number of phases & 4 & phase \\
\hline
\end{tabular}




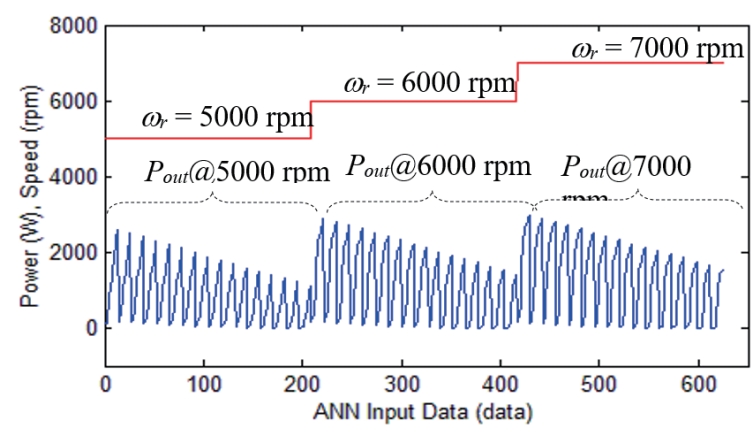

(a)

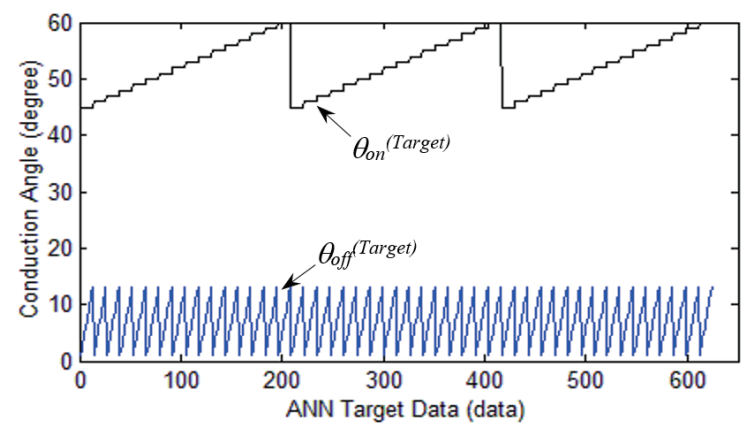

(b)

Fig. 5. (Color online) (a) Training data of ANN: speed $\omega_{r}$ and output power $P_{\text {out }}$ and (b) target output data of ANN: turn-off angle $\theta_{\text {off }}$ (Target) $^{2}$ and turn-on angle $\theta_{\text {on }}{ }^{\text {(Target) }}$.

layers were $L W_{2,1}$ and $L W_{3,1}$, which were both [1 $\left.\times 10\right]$ matrices. Additionally, the output layers contained $b_{3}$ and $b_{2}$ biases for the turn-off and turn-on nodes, respectively. The relevance between the inputs and outputs of the ANN were obtained using Eqs. 6-11.

\subsection{Backpropagation learning algorithm}

To train the ANN, the output power profiles (Fig. 3) were reformatted into training data sets [Fig. 5(a)]. The targeted conduction angles, $\theta_{\text {on }}{ }^{\text {(Target) }}$ and $\theta_{\text {off }}{ }^{\text {(Target) }}$, were then selected [Fig. 5(b)]. The selected target turn-on angles were between 45 and $60^{\circ}$ before the aligned position $\left(\theta_{a}=60,0^{\circ}\right)$, whereas the chosen target turn-off angles were between 1 and $15^{\circ}$ beyond the aligned position. The Levenberg-Marquardt backpropagation learning algorithm was next utilized to adjust the input weight $I W_{1, i}$ and the layer weights $L W_{2,1}$ and $L W_{3,1}$ of the ANN. Figure 6(a) shows the results of the trained ANN. In reference to Fig. 5(a) and $\theta_{o n}{ }^{A N N}$ and $\theta_{\text {off }}{ }^{A N N}$ in Fig. 6(a), if a high output power at the load is required, the conduction angles are wide. On the other hand, if the output power demand at the load is low, the conduction angles become narrow. Figure 6(b) illustrates the trained conduction angle errors, $\theta_{\text {on }}{ }^{(E r r o r)}$ and $\theta_{o f f}{ }^{(E r r o r)}$. The maximum error of the turn-on angle (approximately $9 \%$ ) was near the aligned position $\left(\theta_{a}=60,0^{\circ}\right)$, while its minimum error of approximately $-10 \%$ occurred if the turn-on angle was close to the middle area of the rotor pole $\left(\theta_{a}=45^{\circ}\right)$. The maximum and minimum errors of the turn-off angle were 3 and $-3 \%$ near the aligned position and the middle of the rotor pole, respectively.

\subsection{ANN-incorporated output power control scheme}

The optimal biases and weights of the ANN were acquired at the end of the training. The results were then integrated into the dynamic model of the 8/6 SRG. Figure 7 depicts the model with the ANN-incorporated output power control. The model was developed in MATLAB/ Simulink. Hysteresis current control was used to regulate the phase current. At either a low or medium speed, the output power controller of the SRG was not in use. However, when operating in the single pulse mode, the controller was activated. The phase angles were used to control the 


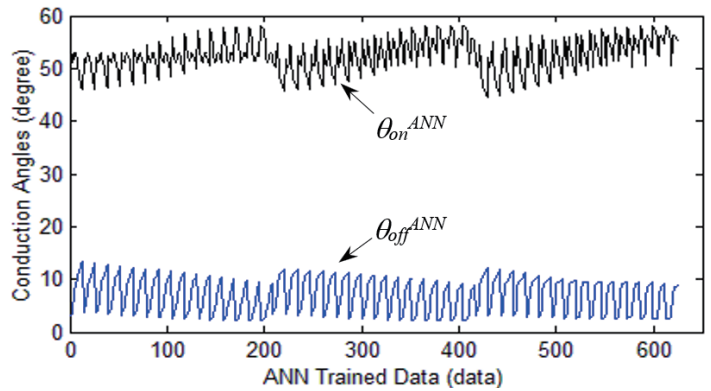

(a)

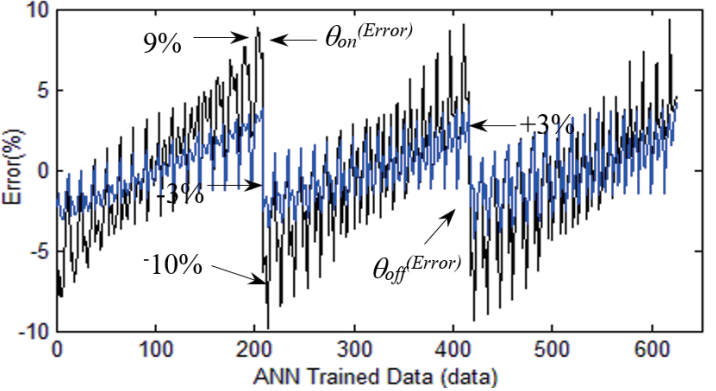

(b)

Fig. 6. (Color online) Results of the trained data set: (a) conduction angles and (b) error (\%).

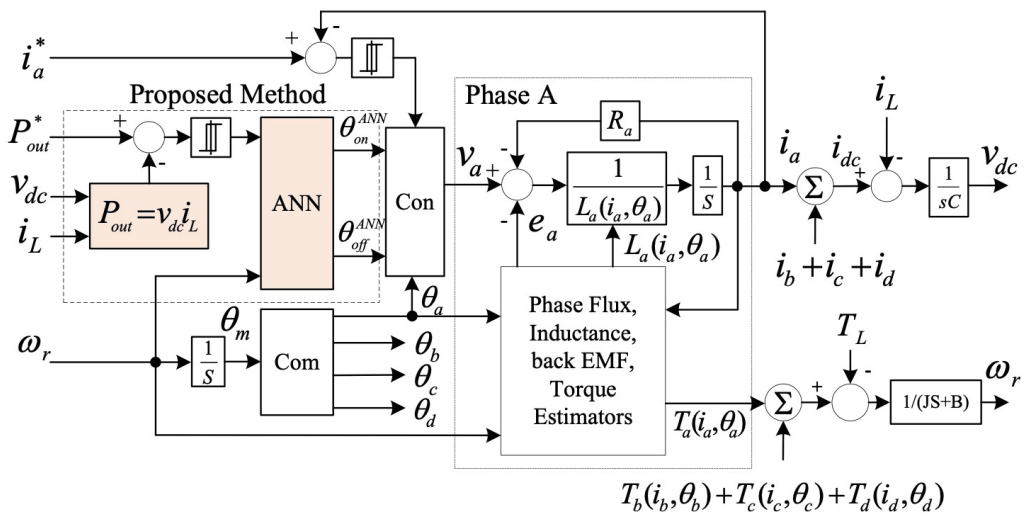

Fig. 7. (Color online) Proposed output power control schematic for an 8/6 SRG.

converter and were compared with the turn-off and turn-on angle commands determined by the ANN. The speed $\omega_{r}$ was converted into a rotor angle $\theta_{m}$ by integration before separation into four phase angles, $\theta_{a}, \theta_{b}, \theta_{c}$, and $\theta_{d}$.

Initially, there was no output power at the load $\left(P_{\text {out }}=0 \mathrm{~W}\right)$, while the output power error $P_{\text {out }}{ }^{\text {(Error })}$ was identical to the command value $P_{\text {out }}{ }^{*}$. The initial conduction angles were determined on the basis of the command values of speed $\omega_{r}$ and power $P_{\text {out }}{ }^{*}$. If the speed and output power commands were $6000 \mathrm{rpm}$ and $1800 \mathrm{~W}$, the ANN-calculated turn-on angle $\theta_{\text {on }}{ }^{A N N}$ and turn-off angle $\theta_{o f f}^{A N N}$ would be 52.14 and $9.77^{\circ}$, respectively. While in operation, all of the phase currents $\left(i_{a}, i_{b}, i_{c}, i_{d}\right)$ flowed in the dc bus as a dc-link current $i_{d c}$. The dc-link current was separated into currents of $i_{C e}$ and $i_{L}$ to charge the capacitor and to supply the dc-load, respectively. The dc-link voltage $v_{d c}$ and dc-load current $i_{L}$ were fed back to compute the average output power $P_{\text {out }}$. The hysteresis power control module was used to regulate the output power. Then, the average output power and speed became the inputs of the ANN. The outputs of the ANN were the turn-off and turn-on angles, which were optimized to the speed and output power commands. In the generating mode, the electromagnetic torques of all phases (i.e., $T_{a}, T_{b}, T_{c}, T_{d}$ ) are negative, while the air gap torque $T_{e}$ is the sum of $T_{a}, T_{b}, T_{c}$, and $T_{d}$. In this research, the moment of inertia of the rotor and the stay loss were excluded. 


\section{Simulation and Experimental Results}

Simulations were performed in MATLAB, and experiments were implemented using a TMS320F2812 digital signal processor (DSP) to control the system. To evaluate the proposed output power control scheme, the simulation and experimental results were compared. The SRG parameters used in the experiment are presented in Table 1.

\subsection{Experimental setup}

Figure 8(a) depicts a schematic of the SRG experimental system, which consisted of an induction motor (ABB) as the SRG prime mover, whose speed was in turn regulated by a threephase inverter (NOVEM). IGBT switches (PIOLAX) were assembled into a four-phase asymmetrical converter, and a three-phase diode bride rectifier was used as the dc source to excite the phase windings. In addition, an SS-200 torque transducer and a TS-2700 torque converter (ONO-SOKKI) were applied to determine the average torque $T_{m}$ of the SRG. The SS-200 transducer was set between two rotor shafts of the SRG and the induction motor. The rotor position and rotation speed of the SRG were determined with an R137 incremental encoder (Gurley Precision Instruments). The system also included a dc-load $R_{L}$ as the resistive load, EXB850 gate drive circuits (Fuji Electric), and L08P150 current sensors (Tamura). Figure 9(a) shows the 8/6 SRG used in the experiment with a torque transducer, the induction motor as a prime mover, and the incremental encoder. Figure 9(b) shows the two-switches-per-phase converter and its controller. C-language was used for DSP programming. The structure of the ANN was also written in the DSP. Figure 10(b) shows how the ANN is incorporated in the control diagram of this study.

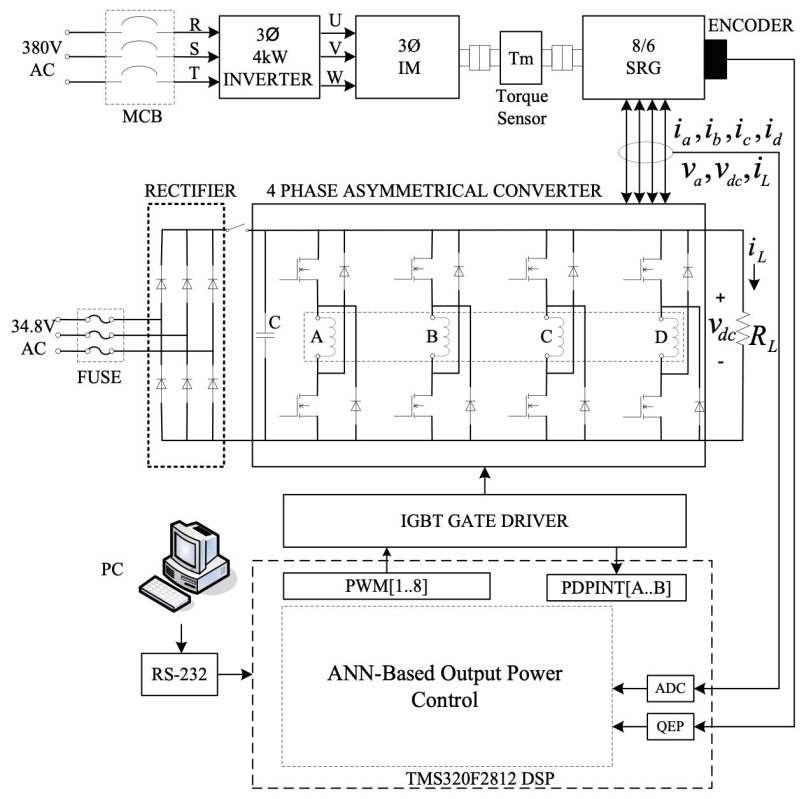

(a)

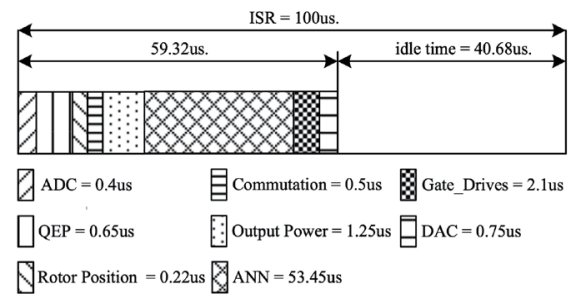

(b)

Fig. 8. Schematic diagram of the SRG experimental system and computational times of the ISR program implemented in the DSP. 
Incremental encoder (QEP1, QEP2)

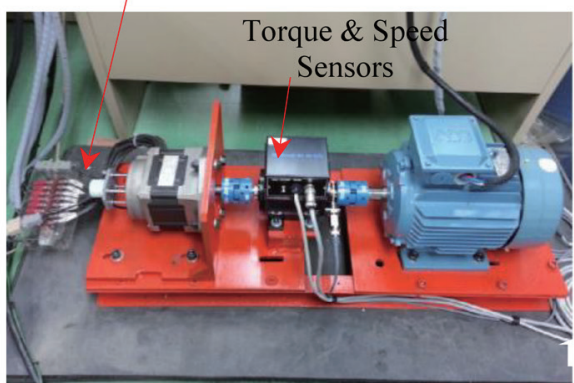

(a)
Current sensor circuits $\left(i_{a}, i_{b}, i_{c}, i_{d}, i_{L}\right)$

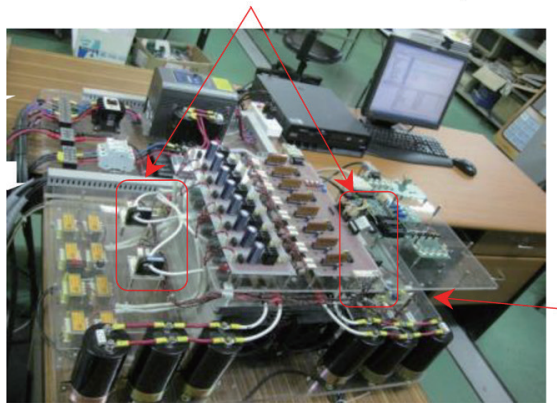

(b)
DC bus voltage Sensor circuit $(v d c)$

Fig. 9. (Color online) Experimental setup: (a) test bench and (b) control and power circuits.

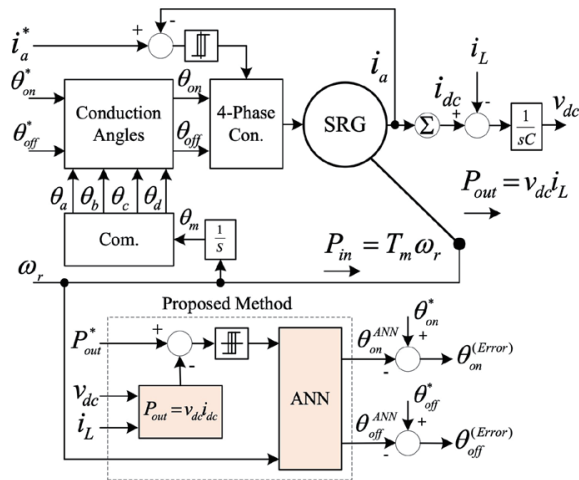

(a)

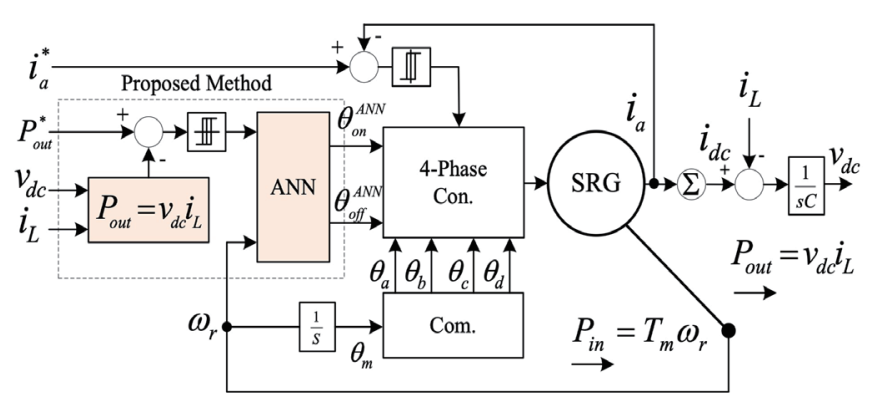

(b)

Fig. 10. (Color online) Schematic diagram of the proposed output power controller showing the ANN block. (a) Offline training of the experimental system and (b) proposed output power controller.

As shown in Fig. $8(\mathrm{~b})$, the switching frequency $\left(f_{s w}\right)$ of the IGBTs was set at $10 \mathrm{kHz}$, resulting in the interrupt service routine (ISR) taking place every $100 \mu \mathrm{s}$. Once the ISR occurred, a 12-bit ADC module sampled the input variables, i.e., $v_{d c}, i_{L}, i_{a}, i_{b}, i_{c}, i_{d}$, and $v_{a}$, and the entire sampling process took approximately $0.4 \mu \mathrm{s}$. The encoder pulses were then counted by a QEP module, and the counting and calculation of the rotor speed took about $0.6 \mu \mathrm{s}$. Then, the encoder pulses were converted into rotor positions, which required approximately $0.22 \mu \mathrm{s}$. The phase angles were next calculated, which required around $0.5 \mu \mathrm{s}$. The output power was computed by multiplying the dc-link voltage $v_{d c}$ and dc-load current $i_{L}$, which took about $1.25 \mu \mathrm{s}$. The calculation of the conduction angles by the ANN required around $53.45 \mu \mathrm{s}$, and the ANN-estimated conduction angles were then applied to the gate drive module. Finally, the calculated values, i.e., the rotor position $\theta_{m}$, phase angles $\left(\theta_{a}, \theta_{b}, \theta_{c}, \theta_{d}\right)$, command angle $c o m_{A}{ }^{*}$, and ANN-estimated conduction angle $\operatorname{com}_{A}{ }^{A N N}$, were sent to the ADC ports of the DSP for measurement. As shown in Fig. 8(b), all the computational steps consumed about $59.32 \mu \mathrm{s}$ with an idle time of $48.68 \mu \mathrm{s}$. Figure 9(a) shows a test bench mounted with the $8 / 6 \mathrm{SRG}$, torque transducer, induction motor, and incremental encoder, while Fig. 9(b) is a photograph of the control and power circuit of the SRG drive system. 


\subsection{Phase current sensor circuits}

To measure the phase currents $\left(i_{a}, i_{b}, i_{c}\right.$, and $\left.i_{d}\right)$ of the proposed SRG and the dc bus current $\left(i_{L}\right)$, current sensor circuits were developed. Tamura L08P150D15 Hall effect current sensors were used in the current sensor circuits. Figure 11 depicts the circuit diagram of the current sensor circuits. As shown in Fig. 9(b), the current sensor circuits are installed in the control and power circuits of the SRG drive system. The phase currents $\left(i_{a}, i_{b}, i_{c}\right.$, and $\left.i_{d}\right)$ and dc bus current $\left(i_{L}\right)$ waveforms will be used to verify the accuracy of the phase current sensor circuits.

\subsection{DC bus voltage sensor circuit}

A de bus voltage sensor circuit was developed to measure the dc bus voltage $\left(v_{d c}\right)$ of the proposed SRG. An ISO124 voltage sensor was applied in the dc bus voltage sensor circuit. Figure 12 depicts the circuit diagram of the dc bus voltage sensor circuit. As shown in Fig. 9(b), the dc bus voltage sensor circuit was installed into the control and power circuits of the SRG drive system.

\subsection{Incremental encoder circuit}

To measure the rotor position $\left(\theta_{m}\right)$ of the proposed SRG, the interface circuit between the incremental encoder and the DSP board was developed. An R137 incremental encoder was used

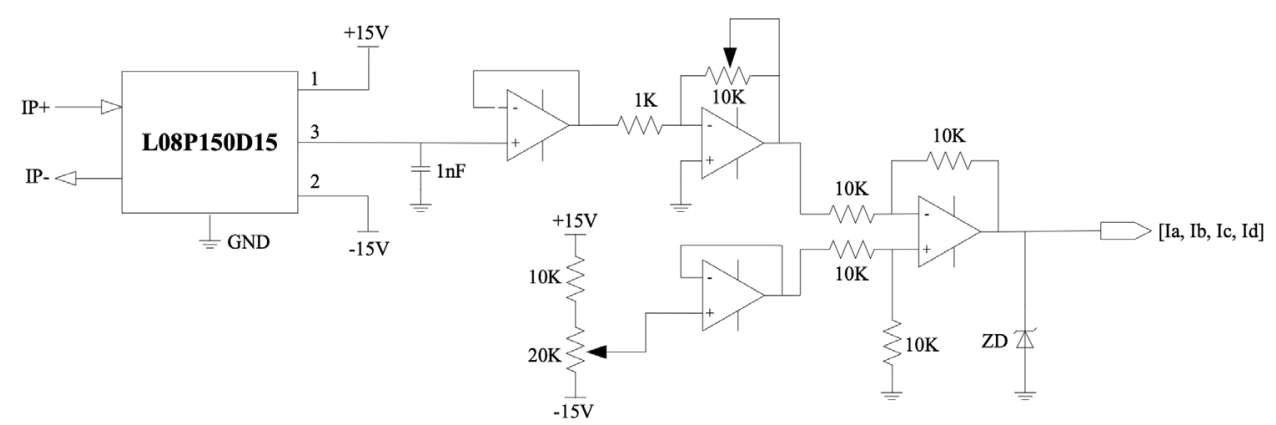

Fig. 11. Phase current sensor circuits.

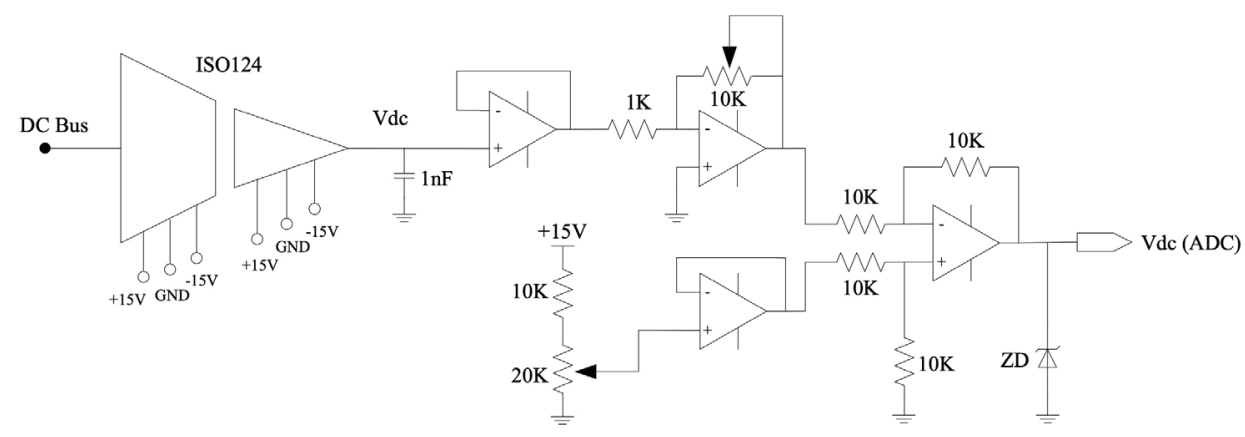

Fig. 12. DC bus voltage sensor circuit. 


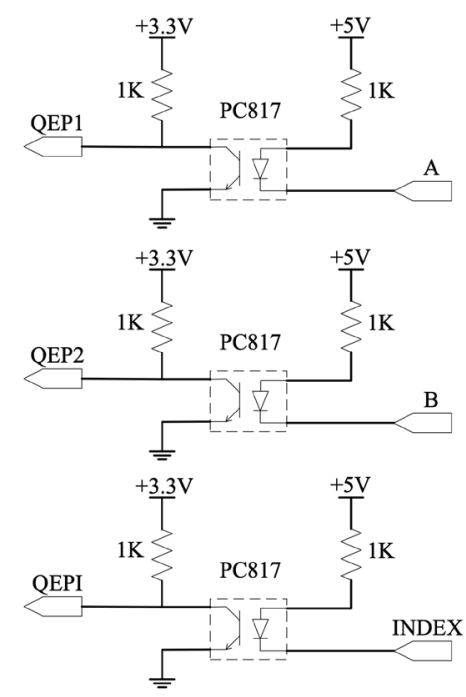

Fig. 13. Interface circuit of incremental encoder and DSP for calculation of SRG rotor position.

to obtain the rotor position and rotation speed of the SRG. Figure 13 depicts the interface circuit of the incremental encoder and DSP for calculation of the rotor position. As shown in Fig. 9(a), the current sensor circuits were equipped in the control and power circuits.

\subsection{Off-line training of ANN-based 8/6 SRG drive}

As shown in Fig. 10(a), an off-line training algorithm of the SRG drive system was introduced to train the weights and biases in the DSP. In the training, a turn-off angle $\theta_{\text {off }}{ }^{*}$ of $10^{\circ}$ and a turnon angle $\theta_{\text {on }}{ }^{*}$ of $50^{\circ}$, were initially selected as the command values. The phase current command $i_{a}{ }^{*}$ was set at a high level of 100 A to make the drive system operate in the single pulse mode. Meanwhile, the speed command $\omega_{r}$ was controlled by the prime mover. The dc-link voltage $v_{d c}$ and load current $i_{L}$ were fed back to determine the output power. The calculated output power $P_{\text {out }}$ and speed $\omega_{r}$ were the inputs of the ANN. The calculated turn-on angle $\theta_{\text {on }}{ }^{A N N}$ and turn-off angle $\theta_{\text {off }}^{A N N}$ were compared with the command values (i.e., 50 and $10^{\circ}$ ). As shown in Fig. 14, the conduction angle errors $\left(\theta_{\text {on }}{ }^{(\text {Error })}, \theta_{\text {off }}{ }^{(E r r o r)}\right)$ were indicators of the accuracy performance of the proposed ANN. To train the weights and biases in the DSP, the speed of the drive system was varied between 5000 and $7000 \mathrm{rpm}$ with an increment of $200 \mathrm{rpm}$. The turn-off angle $\theta_{\text {off }}{ }^{*}$ and turn-on angle $\theta_{\text {on }}$ commands were set at 10 and $50^{\circ}$, respectively, to generate the output power optimally. The load current and dc-link voltage were then fed back to compute the output power, which became an input of the ANN. The ANN then calculated the optimal conduction angles $\left(\theta_{o n}{ }^{A N N}, \theta_{o f f}^{A N N}\right)$ as its outputs from the selected speed and output power.

\subsection{Constant-speed performance}

To evaluate the proposed system under the steady-state condition, the rotor speed was fixed at $6000 \mathrm{rpm}$ and then at $7000 \mathrm{rpm}$. The output power command was also fixed at $1800 \mathrm{~W}$ at both 


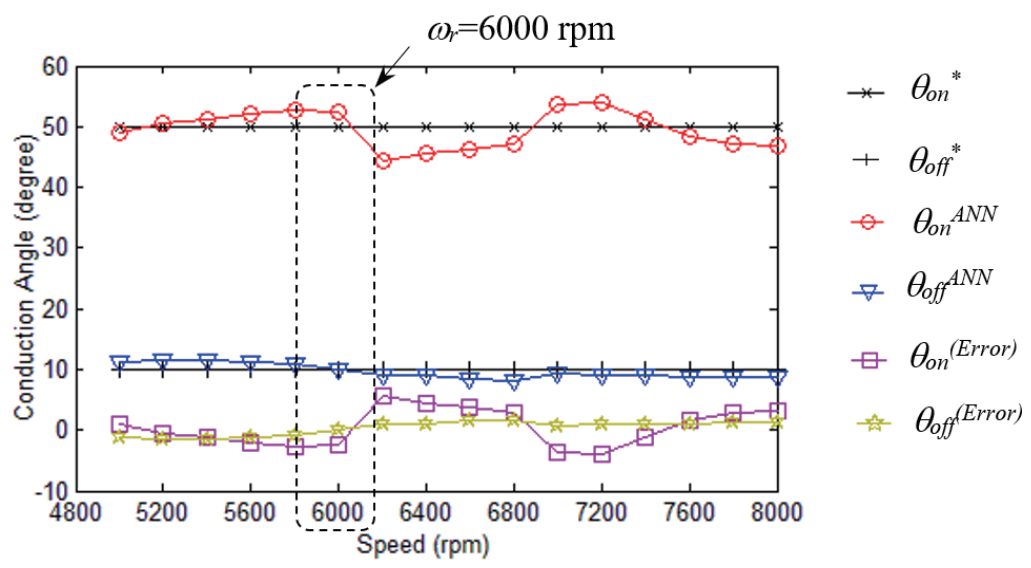

Fig. 14. (Color online) Comparison of command conduction angles and the ANN-calculated conduction angles, and errors at various speeds.

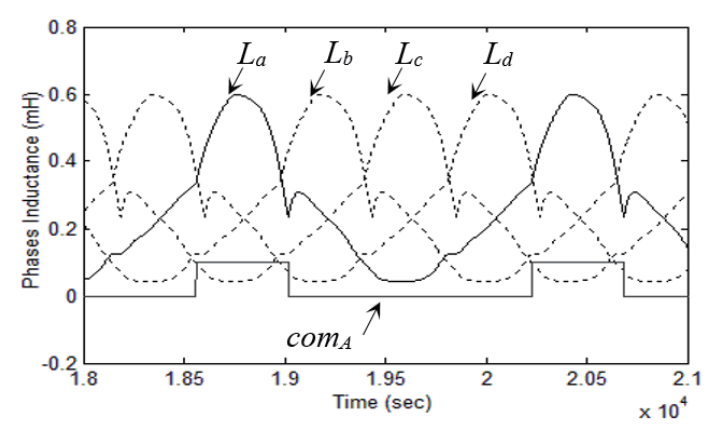

(a)

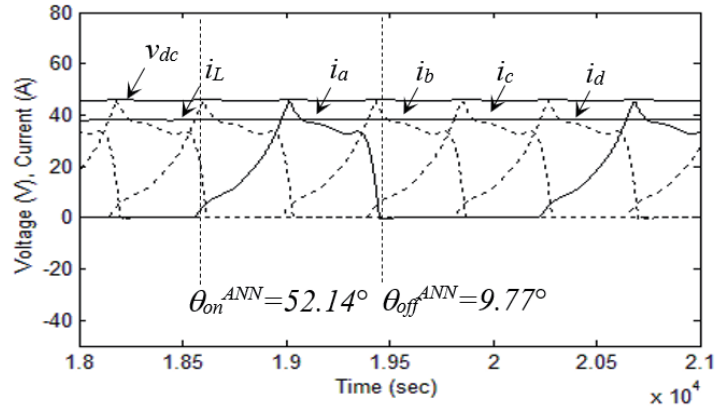

(b)

Fig. 15. Results from simulation of (a) phase inductances $L_{a}, L_{b}, L_{c}, L_{d}$ and commutation angle com ${ }_{A}$, (b) phase currents $i_{a}, i_{b}, i_{c}, i_{d}$, dc-link voltage $v_{d c}$, and dc-load current $i_{L}$ at $6000 \mathrm{rpm}$ and $P_{\text {out }}{ }^{*}=1800 \mathrm{~W}\left(\theta_{\text {on }}{ }^{A N N}=52.14^{\circ}\right.$, $\theta_{\text {off }}^{A N N}=9.77^{\circ}$ ).

operation speeds. At the speed of $6000 \mathrm{rpm}$, the optimal turn-on angle $\theta_{\text {on }}{ }^{A N N}$ and turn-off angle $\theta_{o f f}^{A N N}$ computed by the ANN were 52.14 and $9.77^{\circ}$, respectively. Figure 15(a) depicts the simulation results of the phase inductances $\left(L_{a}, L_{b}, L_{c}, L_{d}\right)$ and commutation angle of phase-A $\left(\operatorname{com}_{A}\right)$. The ANN-calculated turn-on angle was computed just before the aligned position at $\theta_{a}=52.14^{\circ}$, whereas the turn-off angle was computed by the ANN after the aligned position at $\theta_{a}=9.77^{\circ}$.

Figure 15(b) illustrates the simulation results of the dc-link voltage $v_{d c}$, dc-load current $i_{L}$, and the four-phase current $\left(i_{a}, i_{b}, i_{c}, i_{d}\right)$ waveforms at $6000 \mathrm{rpm}$. The average simulated dc-link voltage and dc-load current were $47.12 \mathrm{~V}$ and $38.77 \mathrm{~A}$, respectively, and the average output power at the load was $1827 \mathrm{~W}$ with an error of approximately $1.55 \%$. Figure 16(a) depicts the experimental results at the same speed. The dc-load current $\left(i_{L}\right)$ and average measured dc-link voltage $\left(v_{d c}\right)$ were $39.21 \mathrm{~A}$ and $47.45 \mathrm{~V}$, respectively. The average output power at the load was $1860 \mathrm{~W}$ with an output power error of $3.33 \%$. The simulated and measured waveforms exhibited similar trends. 
At the speed of $7000 \mathrm{rpm}$, the optimal turn-on angle $\theta_{\text {on }}{ }^{A N N}$ and turn-off angle $\theta_{\text {off }}{ }^{A N N}$ computed by the ANN were 53.51 and $9.35^{\circ}$, respectively. Figure 17(a) depicts the simulation results of the phase inductances $\left(L_{a}, L_{b}, L_{c}, L_{d}\right)$ and commutation angle of phase-A $\left(\operatorname{com}_{A}\right)$. The ANN-calculated turn-on angle was before the aligned position $\left(\theta_{a}=53.51^{\circ}\right)$, while the turn-off angle computed by the ANN was beyond the aligned position $\left(\theta_{a}=9.35^{\circ}\right)$. Figure $17(\mathrm{~b})$ illustrates the simulation results of the dc-link voltage $v_{d c}$, dc-load current $i_{L}$, and the four-phase current $\left(i_{a}, i_{b}, i_{c}, i_{d}\right)$ waveforms at $7000 \mathrm{rpm}$. The average simulated dc-link voltage and dc-load current were $48.05 \mathrm{~V}$ and $39.02 \mathrm{~A}$, respectively, and the average output power at the load was $1874 \mathrm{~W}$ with an error of approximately 4.11\%. Figure 16(b) depicts the experimental results, which were measured from the developed current and voltage sensor circuits, at the same speed. The dc-load current $\left(i_{L}\right)$ and average measured dc-link voltage $\left(v_{d c}\right)$ were $39.24 \mathrm{~A}$ and $48.25 \mathrm{~V}$, respectively. The average output power at the load was $1893 \mathrm{~W}$ with an output power error of $5.16 \%$. Furthermore, the simulated and measured waveforms exhibited similar trends. Figures 18(a) and 18(b) compare the simulated and measured waveforms, respectively, of the phase current at 6000 and $7000 \mathrm{rpm}$ under the identical output power command of $1800 \mathrm{~W}$. The waveforms of the phase current varied in response to variations in the conduction angles. The phase current waveforms in Figs. 18(a) and 18(b) confirmed the accuracy of the developed current sensor circuits. This finding indicates that the output power can be manipulated by adjusting the conduction angles.

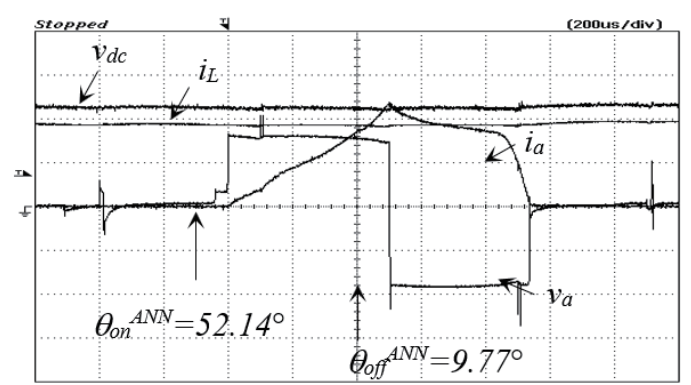

(a)

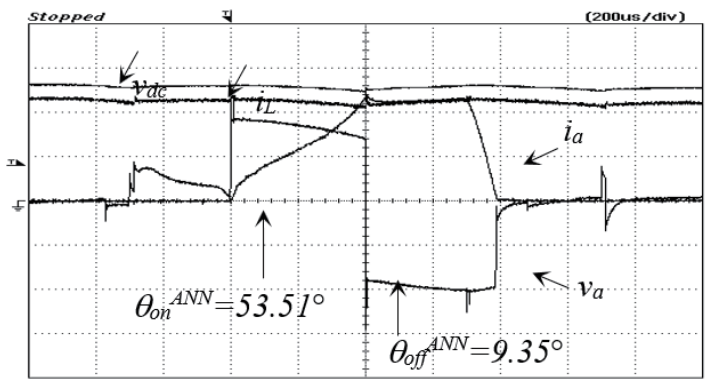

(b)

Fig. 16. Results from measurement of phase $v_{a}$, and dc-link $v_{d c}$ voltage phase $i_{a}$, and dc-load current $i_{L}$ at (a) 6000 $\mathrm{rpm}$ and $P_{\text {out }}{ }^{*}=1800 \mathrm{~W}\left(\theta_{\text {on }}{ }^{A N N}=52.14^{\circ}, \theta_{\text {off }}{ }^{A N N}=9.77^{\circ}\right)$ and $(\mathrm{b}) 7000 \mathrm{rpm}$ and $P_{\text {out }}{ }^{*}=1800 \mathrm{~W}\left(\theta_{\text {on }}{ }^{A N N}=53.51^{\circ}\right.$, $\left.\theta_{o f f}^{A N N}=9.35^{\circ}\right)$.

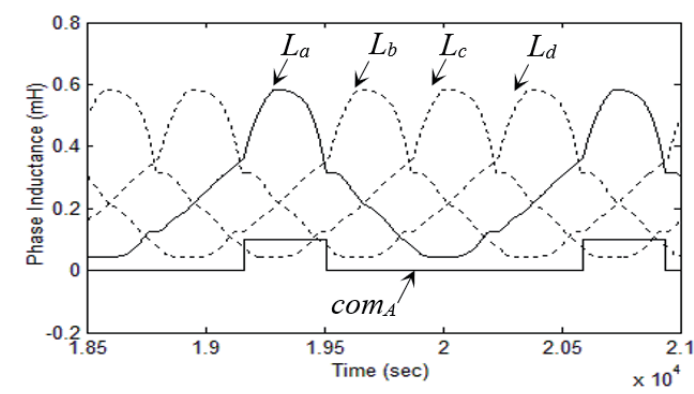

(a)

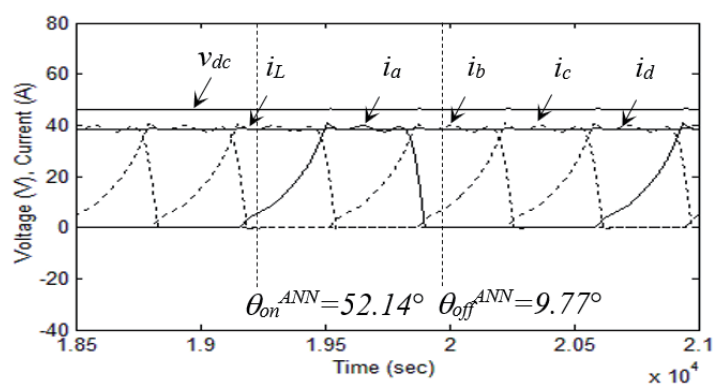

(b)

Fig. 17. Results from simulation of (a) phase inductances $L_{a}, L_{b}, L_{c}, L_{d}$ and commutation angle $\operatorname{com}_{A}$ and (b) phase currents $i_{a}, i_{b}, i_{c}, i_{d}$, dc-link voltage $v_{d c}$, and dc-load current $i_{L}$ at $7000 \mathrm{rpm}$ and $P_{\text {out }}{ }^{*}=1800 \mathrm{~W}\left(\theta_{\text {on }}{ }^{A N N}=53.51^{\circ}\right.$, $\theta_{\text {off }}^{A N N}=9.35^{\circ}$. 


\subsection{Performance at a variable speed}

During the variable-speed operation, the conduction angles were varied according to the speed while the output power remained constant. Initially, the SRG was driven by the prime mover at $7000 \mathrm{rpm}$. The command of the output power was fixed at $1800 \mathrm{~W}$. At this speed, the ANN-calculated conduction angles $\left(\theta_{\text {on }}{ }^{A N N}, \theta_{\text {off }}{ }^{A N N}\right)$ were 53.51 and $9.35^{\circ}$.

The SRG was operated under a steady state (i.e., $7000 \mathrm{rpm}$ ) for $1.38 \mathrm{~s}$ before the speed of the prime mover was reduced to $6000 \mathrm{rpm}$ while the output power remained constant at $1800 \mathrm{~W}$. At $6000 \mathrm{rpm}$, the ANN recalculated the conduction angles $\left(\theta_{o n}{ }^{A N N}, \theta_{o f f}^{A N N}\right)$ and the new conduction angles were 52.14 and $9.77^{\circ}$, respectively.

The SRG was again operated under a steady state (i.e., $6000 \mathrm{rpm}$ ) for $2.21 \mathrm{~s}$ before increasing the speed of the prime mover to $7000 \mathrm{rpm}$, while the output power command remained unchanged at $1800 \mathrm{~W}$. At $7000 \mathrm{rpm}$, the conduction angles returned to 53.51 and $9.35^{\circ}$. The simulated waveforms of the phase current, phase voltage, dc-link voltage, and dc-load current under the variable-speed condition are illustrated in Fig. 19(a). Figure 19(b) shows the average output power at the load.

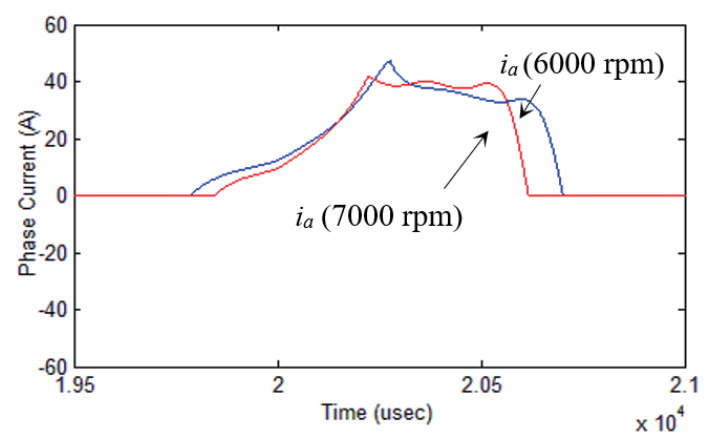

(a)

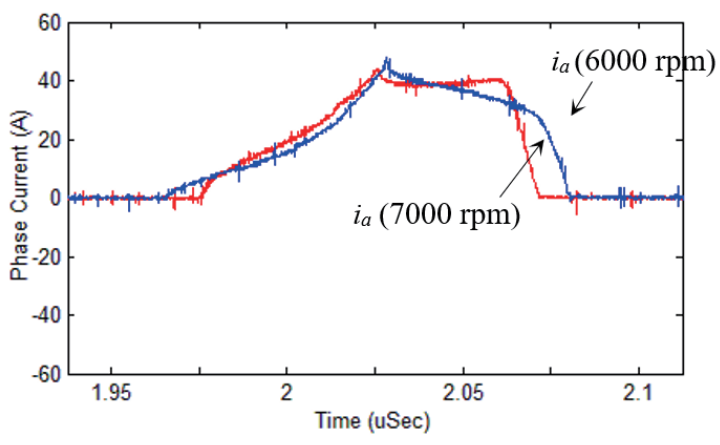

(b)

Fig. 18. (Color online) Results from (a) simulation and (b) measurement of phase current $i_{a}$ at speeds of 6000 and $7000 \mathrm{rpm}$.

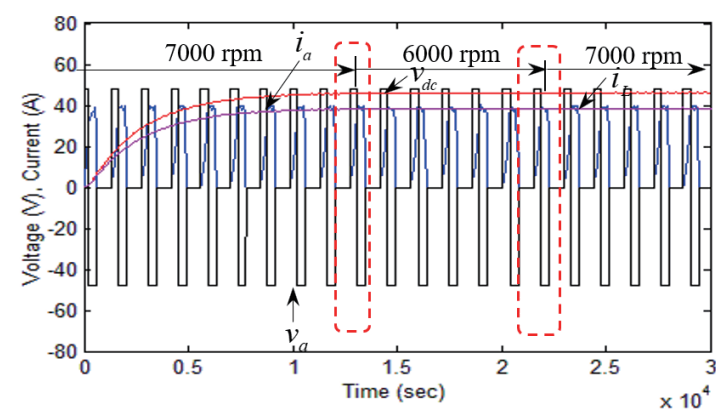

(a)

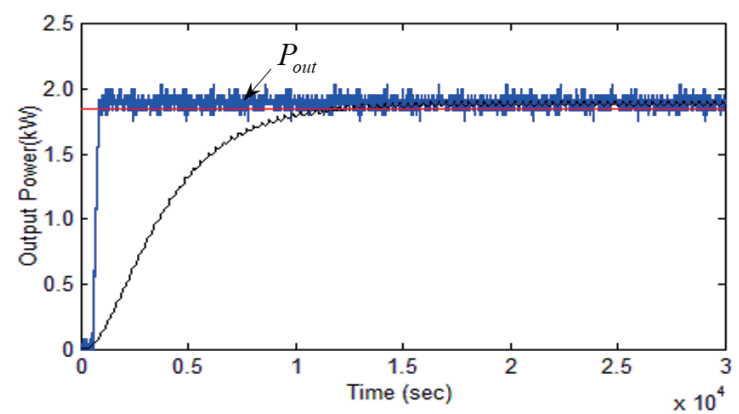

(b)

Fig. 19. (Color online) Simulated results of (a) phase voltage $v_{a}$, dc-link voltage $v_{d c}$, phase current $i_{a}$, and dc-load current $i_{L}$ under variable-speed condition and (b) measured results of average output power at the load. 
However, a dc-link voltage $v_{d c}^{\text {ripple }}$ and load-current ripple $i_{L}{ }_{L}^{\text {ripple }}$ are noticeable in the experiments when the SRG was operated under a steady state and constant speed, a phenomenon that induced disparities between the simulated and measured power outputs. Table 2 presents the errors of the dc-link voltage, dc-load current, and average output power at the speeds of 5000, 6000 , and $7000 \mathrm{rpm}$.

Figure 20 illustrates the relationships between the optimal conduction angles and the average output power determined by the proposed output power control at 5000, 6000, and $7000 \mathrm{rpm}$. It can also be observed that the range of the conduction angles is wide for high output power demand. On the other hand, it is narrow for low output power demand.

Table 2

Errors of the dc-link voltage, dc-load current, and output power.

\begin{tabular}{lccccc}
\hline \multirow{2}{*}{ Speed } & \multicolumn{4}{c}{ Quantities } & \multirow{2}{*}{ Error (\%) } \\
\cline { 2 - 4 } & \multicolumn{2}{c}{ Simulation } & \multicolumn{2}{c}{ Experiments } & \\
& $\theta_{\text {on }}{ }^{A N N}$ & $49.25^{\circ}$ & $\theta_{\text {on }}{ }^{A N N}$ & $49.25^{\circ}$ & 0 \\
& $\theta_{\text {off }}{ }^{A N N}$ & $11.24^{\circ}$ & $\theta_{\text {off }}{ }^{A N N}$ & $11.24^{\circ}$ & 0 \\
$5000 \mathrm{rpm}$ & $v_{d c}$ & $46.95 \mathrm{~V}$ & $v_{d c}$ & $47.24 \mathrm{~V}$ & 0.61 \\
& $i_{L}$ & $39.12 \mathrm{~A}$ & $i_{L}$ & $39.85 \mathrm{~A}$ & 1.83 \\
& $P_{\text {out }}$ & $1814 \mathrm{~W}$ & $P_{\text {out }}$ & $1845 \mathrm{~W}$ & 1.68 \\
\hline \multirow{5}{*}{$6000 \mathrm{rpm}$} & $\theta_{\text {on }}{ }^{A N N}$ & $52.14^{\circ}$ & $\theta_{\text {on }}{ }^{A N N}$ & $52.14^{\circ}$ & 0 \\
& $\theta_{\text {off }}{ }^{A N N}$ & $9.77^{\circ}$ & $\theta_{\text {off }}{ }^{A N N}$ & $9.77^{\circ}$ & 0 \\
& $v_{d}$ & $47.12 \mathrm{~V}$ & $v_{d c}$ & $48.25 \mathrm{~V}$ & 2.34 \\
& $i_{L}$ & $38.77 \mathrm{~A}$ & $i_{L}$ & $39.02 \mathrm{~A}$ & 1.15 \\
& $P_{\text {out }}$ & $1827 \mathrm{~W}$ & $P_{\text {out }}$ & $1882 \mathrm{~W}$ & 2.92 \\
\hline \multirow{5}{*}{$7000 \mathrm{rpm}$} & $\theta_{\text {on }}{ }^{A N N}$ & $53.51^{\circ}$ & $\theta_{\text {on }}{ }^{A N N}$ & $53.51^{\circ}$ & 0 \\
& $\theta_{\text {off }}{ }^{A N N}$ & $9.35^{\circ}$ & $\theta_{\text {off }}{ }^{A N N}$ & $9.35^{\circ}$ & 0 \\
& $v_{d}$ & $47.53 \mathrm{~V}$ & $v_{d}$ & $48.05 \mathrm{~V}$ & 1.14 \\
& $i_{L}$ & $39.61 \mathrm{~A}$ & $i_{L}$ & $39.25 \mathrm{~A}$ & 1.27 \\
& $P_{\text {out }}$ & $1845 \mathrm{~W}$ & $P_{\text {out }}$ & $1890 \mathrm{~W}$ & 2.38 \\
\hline
\end{tabular}

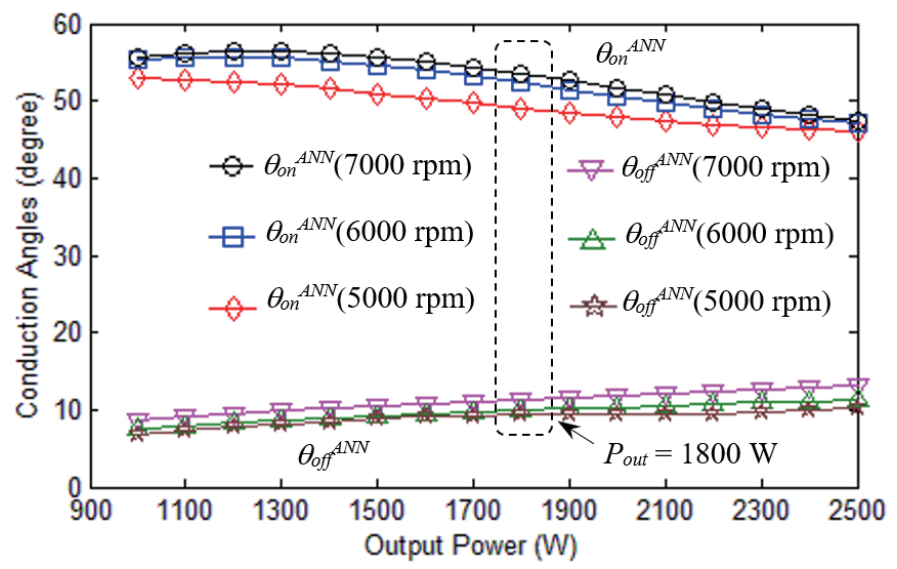

Fig. 20. (Color online) Estimated conduction angles $\left(\theta_{o n}{ }^{A N N}, \theta_{o f f}^{A N N}\right)$ by ANN at 5000, 6000, and $7000 \mathrm{rpm}$. 


\section{Conclusions}

In this paper, the basic knowledge and operation of an SRG and its drive have been provided. The SRG was operated only under single-pulse-mode operation since this mode will have higher efficiency. The SRG operates at high speeds. Nevertheless, in this study, we neglected the output power profiles at low and medium speeds. The phase current and dc-link voltage waveforms were measured from the highly accurate current sensors and voltage sensor circuits. Output power control was implemented by integrating the ANN. The ANN was trained to effectively provide the optimal turn-off and turn-on angles for a certain output power profile. The simulation and experimental results were similar, showing that the proposed method is valid and practical.

\section{References}

1 M. Takeno, A. Chiba, N. Hoshi, S. Ogasawara, M. Takemoto, and M. A. Rahman: IEEE Trans. Ind. Appl. 48 (2012) 1327. https://doi.org/10.1109/tia.2012.2199952

2 B. Fahimi, A. Emadi, and R. B. Sepe: IEEE Trans. Energy Convers. 19 (2004) 116. https://doi.org/10.1109/ tec.2003.822322

3 S. Wang, Q. Zhan, Z. Ma, and L. Zhou: IEEE Trans. Magn. 41 (2005) 501. https://doi.org/10.1109/ tmag.2004.838985

4 K. Kiyota and A. Chiba: IEEE Trans. Ind. Appl. 48 (2012) 2303. https://doi.org/10.1109/tia.2012.2227091

5 X. Liu, K. Park, and Z. Chen: IEEE Trans. Magn. 50 (2014) 1. https://doi.org/10.1109/tmag.2014.2327798

6 V. Valdivia, R. Todd, F. J. Bryan, A. Barrado, A. Lazaro, and A. J. Forsyth: IEEE Trans. Ind. Electron. 61 (2014) 2690. https://doi.org/10.1109/tie.2013.2276768

7 D. A. Torrey: IEEE Trans. Ind. Electron. 49 (2002) 3. https://doi.org/10.1109/41.982243

8 C. Mademlis and I. Kioskeridis: IEEE Trans. Energy Convers. 20 (2005) 556. https://doi.org/10.1109/ tec. 2005.852960

9 P. Asadi, M. Ehsani, and B. Fahimi: Proc. 21th IEEE-APEC Conf. (IEEE, 2006) 1639-1644.

10 R. Cardenas, R. Pena, M. Perez, J. Clare, G. Asher, and P. Wheeler: IEEE Trans. Energy Convers. 20 (2005) 781. https://doi.org/10.1109/tec.2005.853733

11 D. W. Choi, S. I. Byun, and Y. H. Cho: IEEE Trans. Magn. 50 (2014) 1. https://doi.org/10.1109/ tmag.2013.2274174

12 S. Dixon and B. Fahimi: Proc. IEEE Int. Conf. Elect. Mach. Drives (IEEE, 2003) 849-856.

13 V. Nasirian, S. Kaboli, and A. Davoudi: IEEE Trans. Ind. App. 49 (2013) 1031. https://doi.org/10.1109/ tia.2013.2253438

14 I. Kioskeridis and C. Mademlis: IEEE Trans. Power Electron. 21 (2006) 1062. https://doi.org/10.1109/ tpel.2006.876827

15 Y. Sozer and D. A. Torrey: IEEE Trans. Power Electron. 19 (2004) 355. https://doi.org/10.1109/tpel.2003.823178

16 S. Narla, Y. Sozer, and I. Husien: IEEE Trans. Ind. Appl. 48 (2012) 1452. https://doi.org/10.1109/ tia.2012.2209850

17 Z. Li, D. Gao, and J. W. Ahn: Proc. 2012 IEEE Vehicle Power and Propulsion Conf. (IEEE, 2012) 590-593.

18 E. Mese and D. A. Torrey: IEEE Trans. Power Electron. 17 (2012) 66. https://doi.org/10.1109/63.988671

19 E. Echenique, J. Dixon, R. Cardenas, and R. Pena: IEEE Trans. Ind. Electron. 56 (2009) 817. https://doi. org/10.1109/tie.2008.2005940

20 F. Kucuk, H. Goto, H. J. Guo, and O. Ichinokura: Proc. ICEMS Conf. (IEEE, 2007) 503-507.

21 K. M. Rahman, S. Gopalakrishnan, B. Fahimi, A. V. Rajarathnam, and M. Ehsani: IEEE Trans. Ind. Appl. 37 (2001) 904. https://doi.org/10.1109/28.924774

22 H. M. Hasanien and S. M. Muyeen: Elect. Power Syst. Res. 84 (2012) 206. https://doi.org/10.1016/j. epsr.2011.11.019

23 M. Mohseni, N. Niassati, S. Tajik, and E. Afjei: Proc. 3rd PEDSTC Conf. (IEEE, 2012) 330-335.

24 P. N. Materu and R. Krishnan: IEEE Trans. Ind. Appl. 28 (1992) 668. https://doi.org/10.1109/28.137456

25 P. Kerdtuad and S. Kittiratsatcha: Adv. Elect. Comp. Eng. 15 (2015) 41. https://doi.org/10.4316/aece.2015.01006

26 P. Kerdtuad and S. Kittiratsatcha: Proc. 17th ICEMS2014 Conf. (IEEE, 2014) 2839-2845.

27 MATLAB ${ }^{\mathrm{TM}}$ Neural Network Toolbox User's Guide: https://www.mathworks.com/ (accessed May 2021). 


\section{About the Authors}

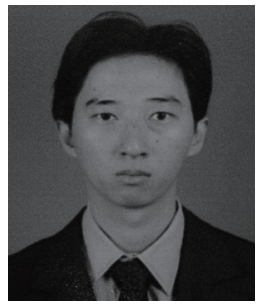

Supat Kittiratsatcha received his B.Eng. degree from Chulalongkorn University, Bangkok, Thailand, in 1996, and his M.S. and Ph.D. degrees in electrical engineering from Rensselaer Polytechnic Institute, Troy, NY, USA, in 1998 and 2002, respectively. Since 2008, he has been an associate professor at the Department of Electrical Engineering, King Mongkut's Institute of Technology Ladkrabang. His research interests include switched reluctance machine design and solid-state lighting.

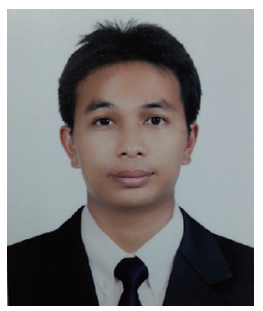

Paiwan Kerdtuad received his B.Eng. degree in electrical engineering from Rajamangala University of Technology Thanyaburi, Thailand, in 2003. He received his M.Eng. and D.Eng. degrees in electrical engineering from King Mongkut's Institute of Technology Ladkrabang, Thailand, in 2011 and 2015, respectively. Currently, he is a lecturer at the Department of Electrical Engineering, Rajamangala University of Technology Isan, Khonkaen Campus, Thailand. His research interests are in power electronics, electrical machines, drive systems, and artificial neural networks.

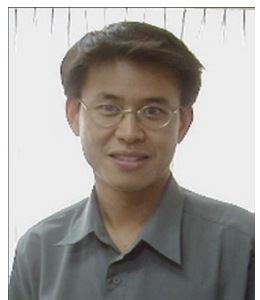

Chanin Bunlaksananusorn received his Ph.D. degree in electrical engineering from The University of Edinburgh, UK, in 1997. He is an associate professor with the Faculty of Engineering, King Mongkut's Institute of Technology Ladkrabang. His research interests are power electronics and energy conversion. 